\title{
Article \\ A Systems Biology Approach to Investigating the Interaction between Serotonin Synthesis by Tryptophan Hydroxylase and the Metabolic Homeostasis
}

\author{
Suhyeon Park ${ }^{1}$, Yumin Kim ${ }^{1}{ }^{(D}$, Jibeom Lee ${ }^{1}$, Jeong Yun Lee ${ }^{1}$, Hail Kim ${ }^{2}$, Sunjae Lee ${ }^{3, *}$ and Chang-Myung Oh ${ }^{1, *}$ \\ 1 Department of Biomedical Science and Engineering, Gwangju Institute of Science and Technology, \\ Gwangju 61005, Korea; suhyeonpark78@gmail.com (S.P.); dbals123@gm.gist.ac.kr (Y.K.); \\ cocacola@gist.ac.kr (J.L); joyun321@gist.ac.kr (J.Y.L.) \\ 2 Graduate School of Medical Science and Engineering, Korea Advanced Institute of Science and Technology, \\ Daejeon 34141, Korea; hailkim@kaist.edu \\ 3 Department of School of Life Sciences, Gwangju Institute of Science and Technology, Gwangju 61005, Korea \\ * Correspondence: leesunjae@gist.ac.kr (S.L.); cmoh@gist.ac.kr (C.-M.O.); Tel.: +82-10-7304-1213 (S.L.)
}

\section{check for}

updates

Citation: Park, S.; Kim, Y.; Lee, J.; Lee, J.Y.; Kim, H.; Lee, S.; Oh, C.-M. A Systems Biology Approach to Investigating the Interaction between Serotonin Synthesis by Tryptophan Hydroxylase and the Metabolic Homeostasis. Int. J. Mol. Sci. 2021, 22, 2452. https://doi.org/ 10.3390/ijms22052452

Academic Editors: Lucia La Sala and Giuseppe Di Giovanni

Received: 19 January 2021

Accepted: 24 February 2021

Published: 28 February 2021

Publisher's Note: MDPI stays neutral with regard to jurisdictional claims in published maps and institutional affiliations.

Copyright: (c) 2021 by the authors. Licensee MDPI, Basel, Switzerland. This article is an open access article distributed under the terms and conditions of the Creative Commons Attribution (CC BY) license (https:// creativecommons.org/licenses/by/ $4.0 /)$.

\begin{abstract}
Obesity has become a global public health and economic problem. Obesity is a major risk factor for a number of complications, such as type 2 diabetes, cardiovascular disease, fatty liver disease, and cancer. Serotonin (5-hydroxytryptamine [5-HT]) is a biogenic monoamine that plays various roles in metabolic homeostasis. It is well known that central 5-HT regulates appetite and mood. Several 5-HT receptor agonists and selective serotonin receptor uptake inhibitors (SSRIs) have shown beneficial effects on appetite and mood control in clinics. Although several genetic polymorphisms related to 5-HT synthesis and its receptors are strongly associated with obesity, there is little evidence of the role of peripheral 5-HT in human metabolism. In this study, we performed a systemic analysis of transcriptome data from the Genotype-Tissue Expression (GTEX) database. We investigated the expression of 5-HT and tryptophan hydroxylase (TPH), the rate-limiting enzyme of 5-HT biosynthesis, in the human brain and peripheral tissues. We also performed differential gene expression analysis and predicted changes in metabolites by comparing gene expressions of tissues with high TPH expression to the gene expressions of tissues with low TPH expression. Our analyses provide strong evidence that serotonin plays an important role in the regulation of metabolic homeostasis in humans.
\end{abstract}

Keywords: serotonin; metabolic homeostasis; systems biology

\section{Introduction}

Obesity is defined as excessive accumulation of body fat, which presents several risks [1]. It is the major risk factor for a number of complications such as type 2 diabetes, cardiovascular disease, fatty liver disease, and cancer [2]. The prevalence of obesity has increased dramatically and has become a global public health problem [2]. For this reason, the American Medical Association (AMA) recognized obesity as a complex, chronic disease [3]. For the prevention and treatment of this disease, scientists have tried to understand the mechanisms of regulating energy homeostasis and find a way to maintain a balance between energy intake and energy expenditure $[4,5]$.

Serotonin (5-hydroxytryptamine, 5-HT) is a biogenic monoamine that is highly conserved between nematodes and vertebrates [6]. 5-HT is synthesized from tryptophan catalyzed by the rate-limiting enzyme, tryptophan hydroxylase (TPH) [7]. TPH exists in two isoforms, TPH1 and TPH2. TPH1 is mainly expressed in peripheral tissues and pineal gland [8]. TPH2 is abundant in the serotonergic neurons in the brain and myenteric plexus [9]. Recent studies have revealed various roles of serotonin in the regulation of energy homeostasis $[7,10,11]$. In the brain, serotonin controls anxiety and appetite-related 
behaviors as a neurotransmitter [10]. Several serotonin receptor agonists and selective serotonin receptor uptake inhibitors (SSRIs) targeting central serotonin have been widely used in the clinical field and have revealed strong associations with body weight changes [10]. For example, serotonin receptor (HTR) $2 \mathrm{C}$ is a G protein-coupled receptor that plays a role in appetite, eating behavior, and energy metabolism [7,12]. HTR2C polymorphisms have also shown strong associations with obesity and metabolic disorders [13,14], and the HTR2C agonist has shown a significant weight-loss effect in clinical studies [15].

Peripheral serotonin also has shown integral roles in various physiological and pathological regulation $[7,10,11]$. More than $90 \%$ of peripheral serotonin is synthesized and secreted from enterochromaffin cells in the gut and stored in platelets [7]. Platelets uptake 5-HT from the plasma and release 5-HT in response to specific conditions such as tissue injury and acute inflammation [16,17]. Furthermore, gut-derived serotonin (GDS) promotes gluconeogenesis and lipolysis in hepatocytes under fasting conditions [18]. GDS also plays an important role in lipid accumulation in the liver. Inhibition of GDS synthesis or HTR2A signaling prevents high-fat diet (HFD) induced hepatic steatosis in mice models [19]. Serotonin derived from other peripheral tissues has shown various effects on metabolism [20-23]. Pancreatic beta cell-derived serotonin regulates beta cell proliferation and insulin secretion during pregnancy $[20,21]$. Adipocyte-derived serotonin (ADS) regulates lipogenesis in white adipose tissue (WAT) and thermogenesis in brown adipose tissue (BAT) [22,23]. Recent studies have reported that the gut microbiome controls GDS synthesis and serotonin level changes due to gut microbiota dysbiosis results in obesity and its related metabolic dysfunctions [24,25].

Genetic studies have suggested statistical evidence for the role of serotonin in metabolic disorders in humans [26-29]. Recent monozygotic study reported that serotonin transporter gene (SCL6A4) promoter hypermethylation has strong association with body weight and body mass index (BMI) [26]. Genetic polymorphisms and DNA hypermethylation of the HTR2A gene have been associated with obesity and metabolic syndrome [27]. Singlenucleotide polymorphisms (SNPs) in HTR2A and HTR2C have significant associations with obesity and type 2 diabetes [28]. SNPs in TPH1 and HTR2B displayed significant associations with weight gain during pregnancy [29].

Animal studies and human genomic studies have demonstrated that serotonin regulates glucose, lipid metabolism, and energy expenditure [7,11]. Although some human studies reported that plasma 5-HT had associations with obesity [30,31], more evidence is needed to support the role and potential mechanisms of 5-HT in human peripheral tissues. In this study, we aimed to analyze the gene expressions of the human brain and peripheral tissues according to TPH expression. To accomplish this, we used the Genotype-Tissue Expression (GTEX) database [32].

\section{Results}

\subsection{TPH Expression in Human Tissue}

TPH is the rate-limiting enzyme in the biosynthesis of serotonin. In the brain, serotonin levels are directly related to TPH activity [33]. In peripheral tissues, serotonin levels are related to circulating serotonin levels from the gut (circulating serotonin) and TPH activity of the peripheral tissues (local serotonin) [34]. To assess the roles of serotonin in energy metabolism, we analyzed TPH mRNA expression in the human tissues from the GTEx dataset. First, we checked TPH1 and TPH2 expression in the brain and peripheral tissues (Figure 1 and Supplementary Figures S1 and S2). TPH2 was mostly expressed in central nervous system (Figure 1A). Gastrointestinal tracks expressed TPH1, and several peripheral tissues, such as adipose tissues, expressed TPH1 (Figure 1B). These expressions support previous reports about the existence and autocrine/paracrine role of ADS as well as GDS [19,22]. 
(A)

TPH1 expression

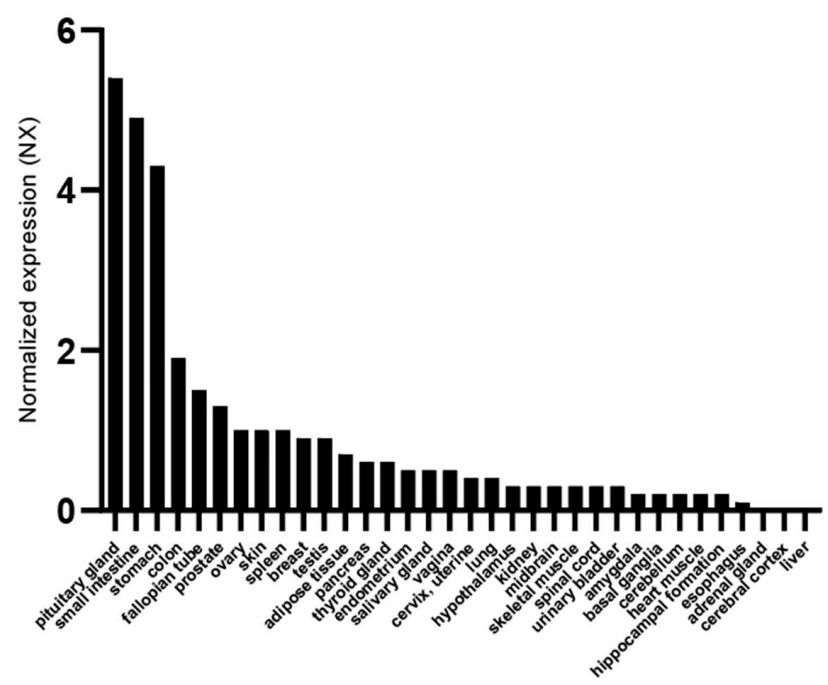

(B)

TPH2 expression

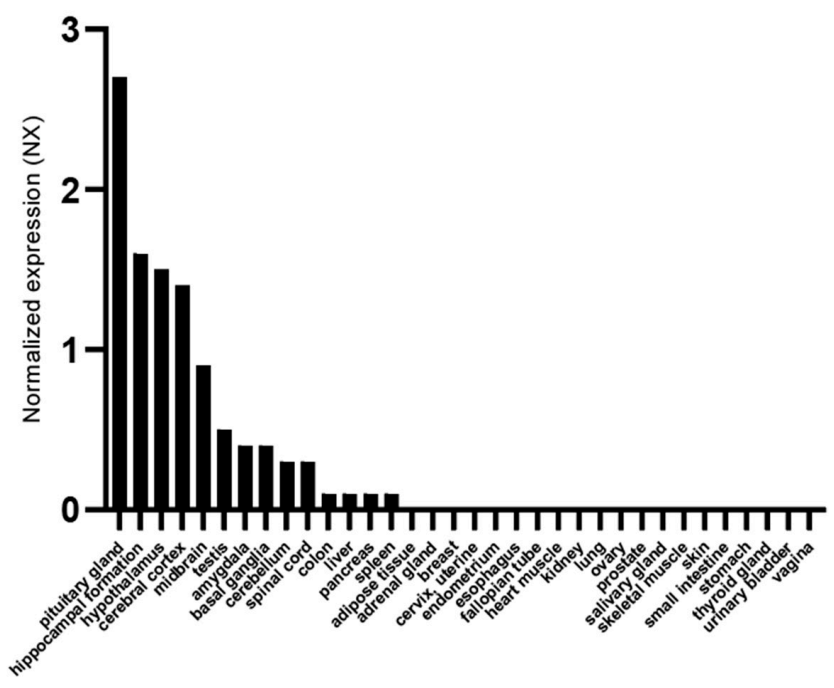

Figure 1. TPH expression in human tissues of the GTEx data. (A) TPH1 expression in human tissues. (B) TPH2 expression in human tissues. TPH: tryptophan hydroxylase.

Previous postmortem analysis of brain tissues reported that TPH2 mRNA expression is abundant in the dorsal raphe nucleus, median raphe nucleus, and raphe nuclei-containing regions such as pons and medullar, not the pituitary gland [35,36]. Although TPH1 is mainly expressed in peripheral tissues, some papers have already reported the existence of TPH1 in the brain, especially in the pituitary gland [37-39]. Our results showed that the pituitary gland expressed TPH1 as well as TPH2, and the expression levels were higher than those in other tissues (Figure 1). This suggests that serotonin might play a more important role in the pituitary gland and hypothalamus-pituitary axis regulation than we already thought.

\subsection{Transcriptome Analysis in Brain According to TPH2 Expression}

To investigate the role of serotonin in the brain, we selected 10 brain tissues with highly expressed TPH2 mRNA and 10 brain tissues with lowly expressed TPH2 mRNA 
in the brain transcriptome of GTEx dataset. Differentially expressed gene (DEG) analysis between these two groups revealed that high TPH2 groups showed downregulation of lipid metabolism related genes (Figure 2A,B). For example, adipogenesis marker genes (FAB4 and ADIPOQ) and driver gene (PPARG) are decreased in high TPH2 group [40]. Fatty acid oxidation (FAO) related genes (CIDEA, UCP2, ANGPTL4) are also decreased in high TPH2 group [41]. Gene Set Enrichment assay (GSEA) revealed that central serotonin has a negative association with fatty acid metabolism, adipogenesis, and glycolysis (Figure 2C,D). Lipid in the brain is a key component of neuronal structure and brain development [42]. Thus, our results imply that serotonin has a significant role in lipid processing in the brain, which regulates systemic metabolism [42]. Gene Ontology (GO) analysis supported this implication. GO analysis revealed that several biological functions associated with sensory perception and neuronal development changed according to TPH2 expression in brain (Figure 2E).

(A)

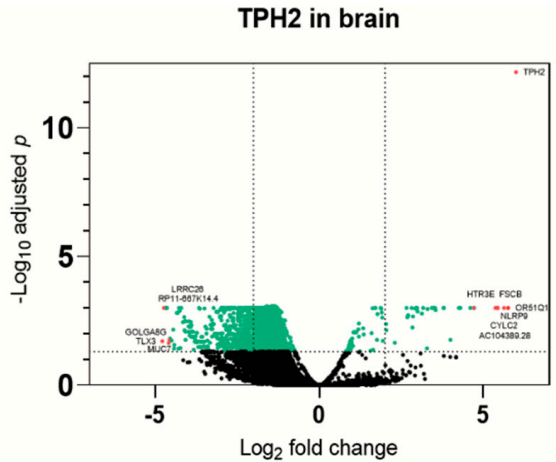

(C)

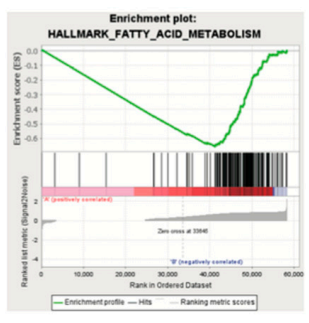

(B)

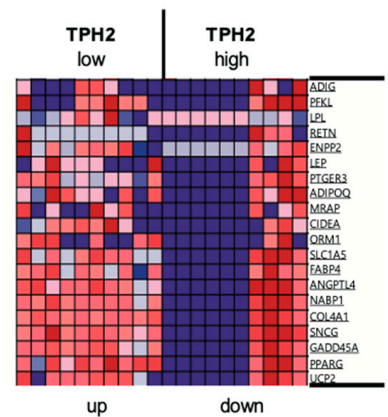

(D)

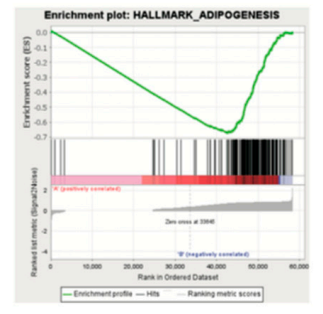

up



(E)
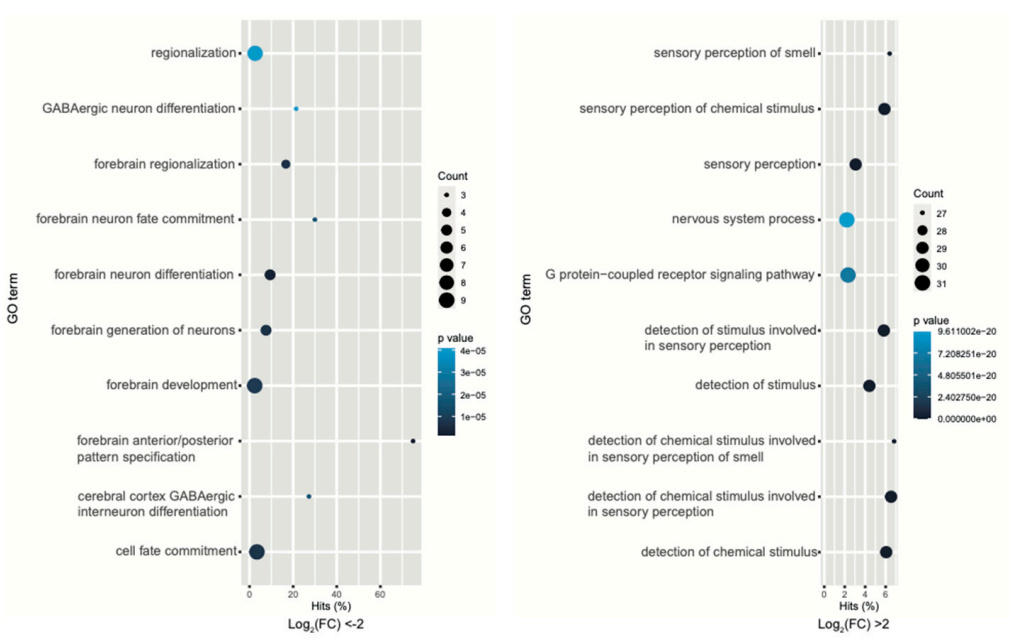

Figure 2. Gene expression changes in brain according to TPH2 expression $(n=10$ per group). (A) Volcano plot of the significantly differentially expressed genes (DEGs). (B) Heatmap of DEGs. (C-E) DEGs were analyzed by Gene set enrichment analysis. (C) The enrichment plot for fatty acid metabolism and adipogenesis. (D) Bar plot depicting the normalized enrichment scores (NES). (E) Dot plot for enriched gene ontology pathways from GSEA results. 


\subsection{Transcriptome Analysis in Intestine and Adipose Tissue According to TPH1 Expression}

The major source of peripheral serotonin is enterochromaffin cells in the gut [7]. This GDS directly regulates intestinal motility and inflammation [43]. As a circulating hormone, GDS inhibits bone formation [44] and regulates lipid metabolism in the adipose tissue and liver $[18,19]$. To evaluate the role of serotonin in the gut, we selected 10 samples with highly expressed Tph1 mRNA and 10 samples with lowly expressed Tph1 mRNA from the small intestine and colon transcriptome data from the GTEx database. Figure 3 and Supplementary Figure S3 show highly differentially expressed genes from the small intestine and colon dataset. Intriguingly, most highly expressed genes in the high TPH1 group have important roles in pancreatic endocrine cell development (PDX1, PAX4, NEUROD1, NEUROG3) and hormonal secretion (CHGA, SST, DPP4) (Figure 3A,B). GSEA also showed that TPH1 expression was positively correlated with pancreatic beta cell related genes (Figure 3C,D). Previously, our group reported that pancreatic beta cell-derived serotonin regulates beta cell proliferation and insulin secretion [20,45]. However, the role of GDS in pancreatic beta cell has not yet been discovered. Further studies are needed to investigate the role of GDS in pancreatic beta cell. Conversely, these patterns suggest the importance of GDS in gut functions as an endocrine organ. Actually, gut is the largest endocrine organ in the human body [46], and many genes related to pancreatic beta cell also play an important role in gut endocrine functions. For example, Pdx1 deletion in the gut resulted in a significant reduction of mRNA abundance of gastric inhibitory peptide and somatostatin and decreased intestinal alkaline phosphate activity in the mouse gut [47]. Ngn3 deleted mice showed impaired endocrine progenitor cells, gastrin-secreting cells ( $\mathrm{G}$ cells), and somatostatin-secreting cells (D cells) in the gut [48].

GSEA analysis also showed a positive correlation with fatty acid metabolism and the K-RAS signaling pathway (Figure 3C,D). KRAS signaling plays various roles in cell proliferation, apoptosis, and angiogenesis [49]. This gene is a well-known oncogene [50]. Mutations in this gene and activated KRAS signaling are one of the most common causes of colon cancer development [50,51]. This suggests that high serotonin levels in the gut may act as a cancer driver. Some studies have reported the role of serotonin in colon cancer [52-54]. Tutton et al. reported that serotonin supplementation promoted the proliferation of colon cancer cells [53]. GO analysis showed several pathways related to nutrient metabolism, organ development, and inflammation (Figure 3E).

\subsection{Transcriptome Analysis in White Adipose Tissue According to TPH1 Expression}

ADS regulates adipocyte differentiation and metabolism via autocrine/paracrine signaling [55]. Previously, we reported that serotonin regulates de novo lipogenesis in white adipose tissue and thermogenesis in brown adipose tissue in mice [22,23]. To evaluate the role of ADS in human adipose tissue, we selected 10 samples with highly expressed Tph1 mRNA and 10 samples with lowly expressed Tph1 mRNA from white adipose tissues (omentum and subcutaneous tissue beneath the leg's skin) transcriptome data from the GTEx database. Figure 4 shows the results of DEG, GSEA, and GO analysis. The high TPH1 expression group showed significant metabolism-associated gene expression changes compared to the low TPH1 expression group (Figure 4A,B). RNASE13 is a ribonuclease, and this gene, which has the highest fold changes in GSEA, has shown significant associations with diabetes [56]. The transcription factor SIM1 plays a role in appetite control, and genetic variations in the SIM1 genes have shown significant associations with pediatric obesity [57]. GSEA analysis revealed that TPH1 expression in adipose tissue was positively correlated with pancreatic beta cell specific genes, fatty acid metabolism, and KRAS signaling (Figure 4C,D). Previously, we reported that pancreatic beta cell-derived serotonin regulates beta cell proliferation and insulin secretion $[20,45,58]$. However, there are no reports about the role of ADS in pancreatic beta cell. High TPH1 adipose tissues showed decreased KIRREL2 mRNA expression. KIRREL2, a novel immunoglobulin superfamily gene, is primarily expressed in pancreatic beta cells and regulates insulin secretion $[59,60]$. Further studies are needed to explore the role of GDS in pancreatic beta cell based on these 
changes in gene set analysis. GO analysis (Figure 4E) revealed the immune systems and organ development. Interestingly, developmental categories in other peripheral tissues such as lung, kidney, and pancreas have significant associations with TPH1 expression in adipose tissue. This suggests an important endocrine role of adipose tissue in the human body.

(A)

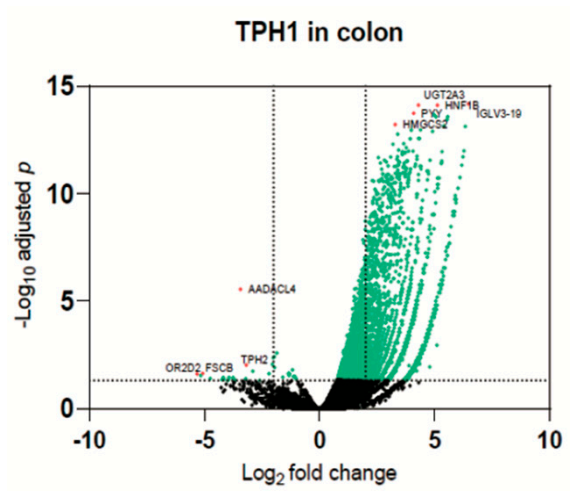

(C)
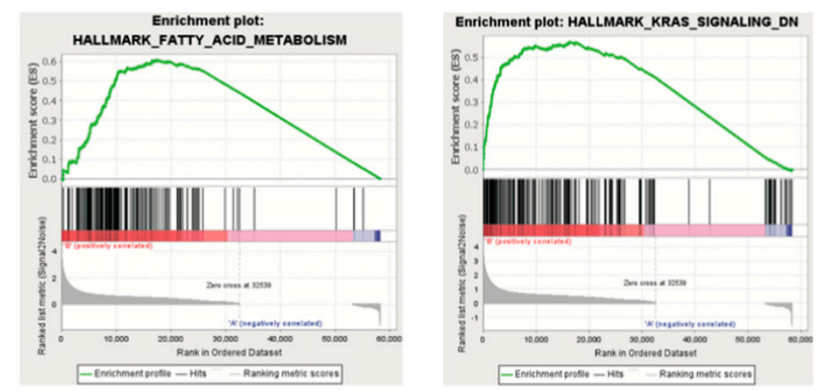

(B)

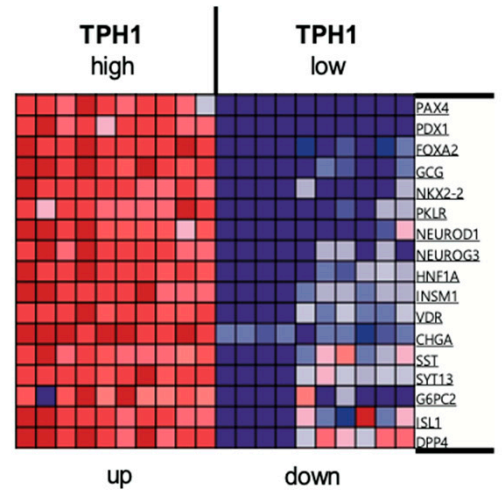

(D)

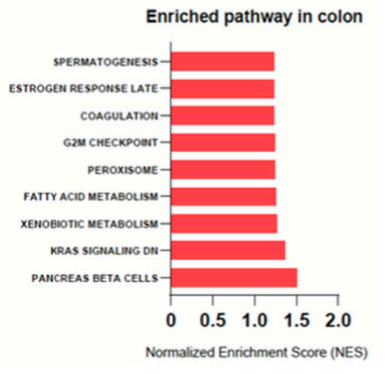

(E)

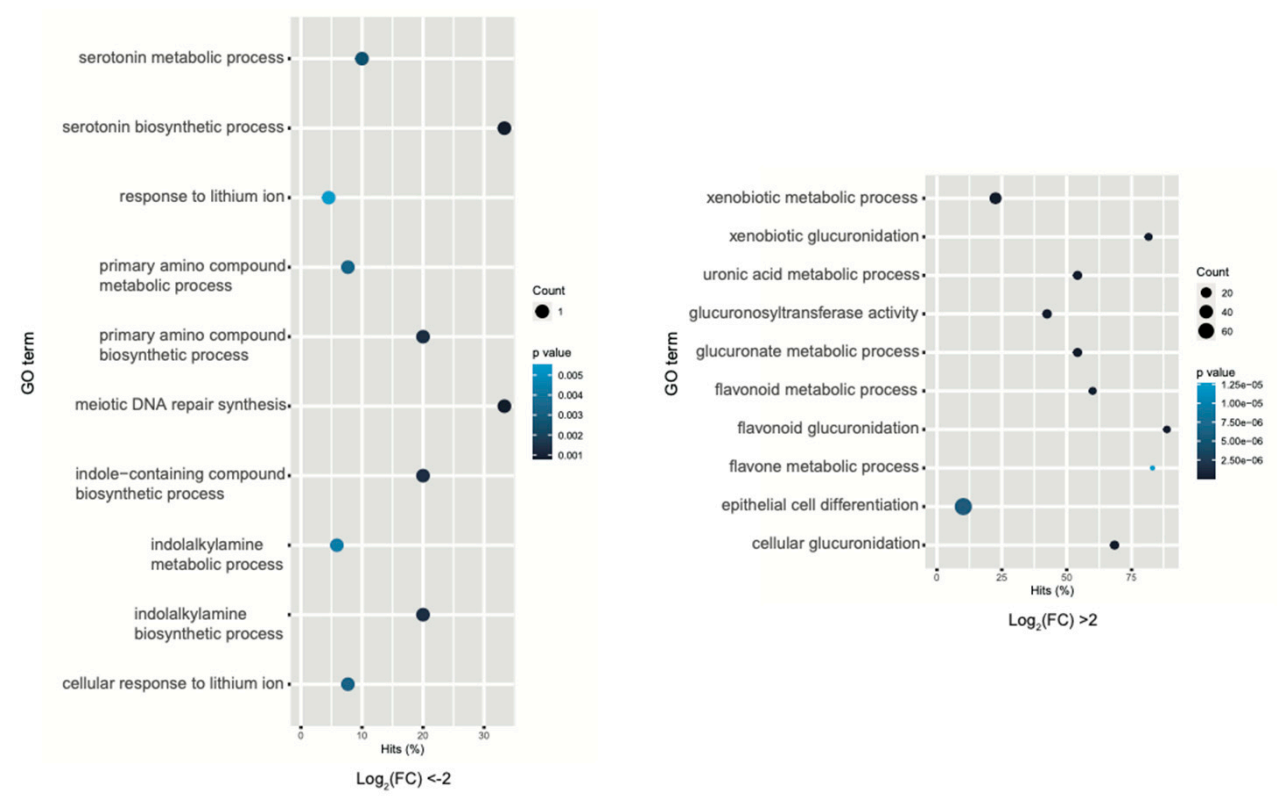

Figure 3. Gene expression changes in colon according to TPH1 expression ( $n=10$ per group). (A) Volcano plot of the significantly differentially expressed genes (DEGs). (B) Heatmap of DEGs. (C-E) DEGs were analyzed by Gene set enrichment analysis. (C) The enrichment plot for fatty acid metabolism and K-RAS signaling. (D) Bar plot depicting the normalized enrichment scores (NES). (E) Dot plot for enriched gene ontology pathways from GSEA results. 
(A)

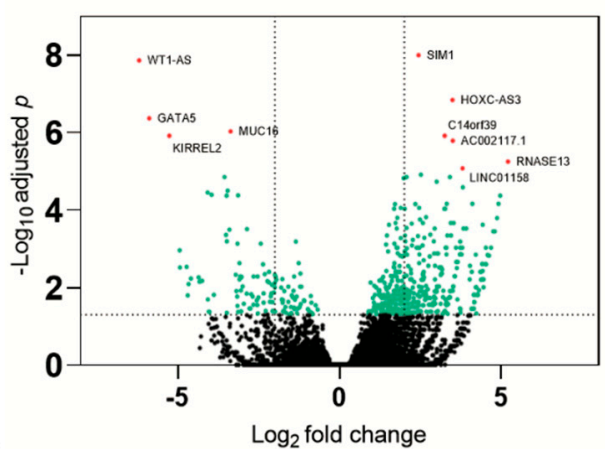

(C)
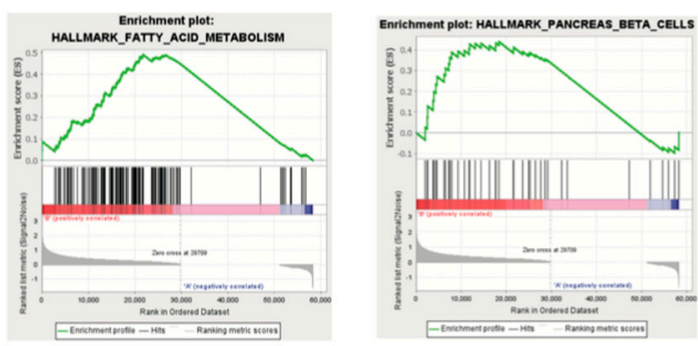

(B)

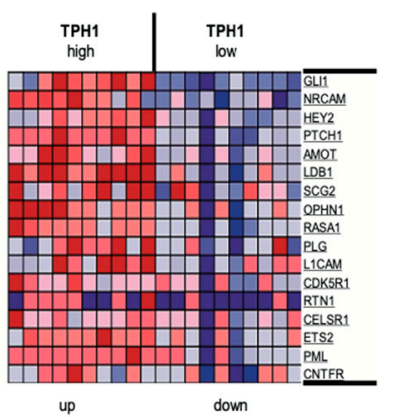

(D)

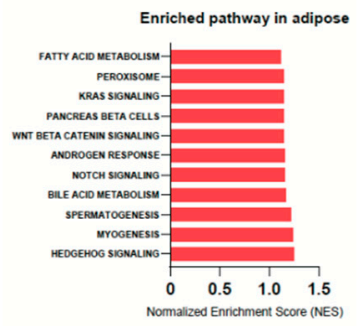

(E)
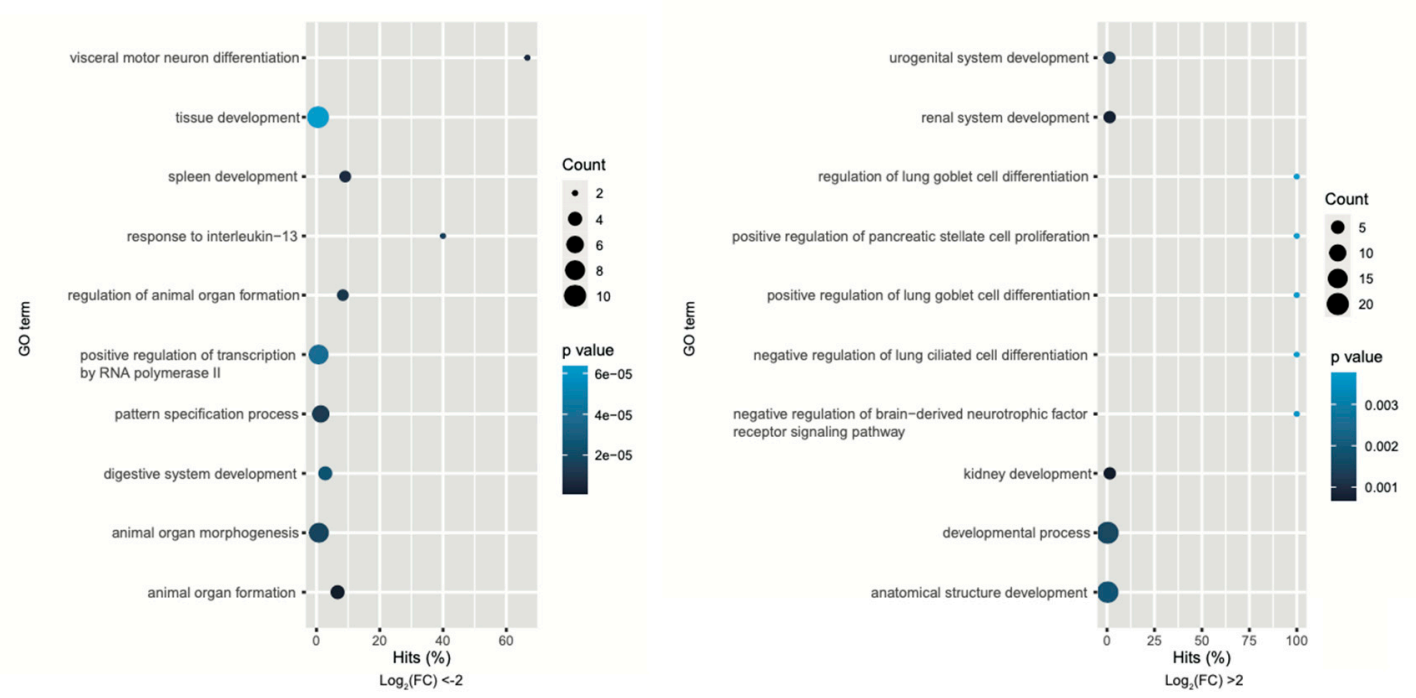

Figure 4. Gene expression changes in adipose tissue according to TPH1 expression ( $n=10$ per group). (A) Volcano plot of the significantly differentially expressed genes (DEGs). (B) Heatmap of DEGs. (C-E) DEGs were analyzed by gene set enrichment analysis. (C) The enrichment plot for fatty acid metabolism and pancreas beta cells. (D) Bar plot depicting the normalized enrichment scores (NES). (E) Dot plot for enriched gene ontology pathways from GSEA results.

\subsection{The Role of Serotonin in Mitochondria}

Animal studies have revealed that serotonin is an important regulator of mitochondrial function [61-63]. Serotonin increases mitochondrial biogenesis through HTR2A in cortical neurons and regulates mitochondrial transport in hippocampal neurons through HTR1A [61]. HTR3 and HTR4 localize to the mitochondrial membrane and regulate mitochondrial functions by $\mathrm{Ca}^{2+}$ signaling and mitochondrial permeability transition pore (mPTP) opening [63]. Serotonin also acts as an antioxidant in brain and peripheral tissues, such as pancreatic beta cell and kidney $[58,64,65]$. Caenorhabditis elegans studies reported that serotonin is required for neuroendocrine communication against mitochondrial proteotoxic stress $[66,67]$. 
To investigate the role of serotonin in human mitochondria, we analyzed the expressions of genes related to mitochondrial biogenesis and quality control in human tissue transcriptome from the GTEx dataset. Figure 5 shows a heatmap plot of the DEG analysis. In the brain, TPH2 expression showed negative associations with most genes related to mitochondrial biogenesis, ATP biosynthesis, and mitochondrial quality control.

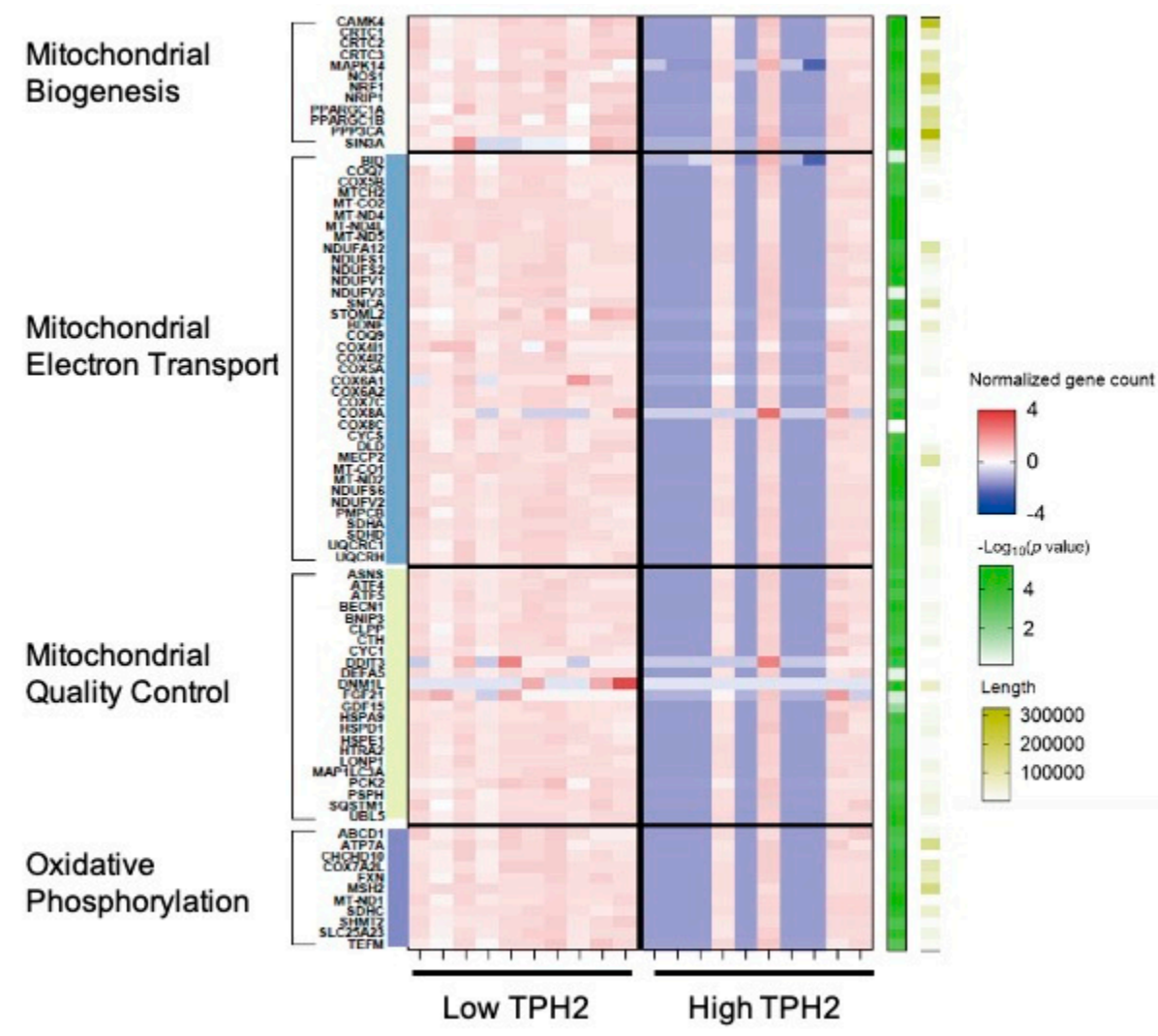

Figure 5. The heat map of DEGs related to mitochondrial biogenesis, energy metabolism, and mitochondrial quality control according to TPH2 expression in brain ( $n=10$ per group).

\subsection{Metabolite Changes According to TPH Expression}

Serotonin is the main tryptophan metabolite by TPH and is metabolized to 5-hdryoxyindole acetaldehyde by monoamine oxidase [8]. Numerous studies have shown that gut microbes can metabolize tryptophan in the gut and affect host metabolism by changing host tryptophan metabolites $[25,68]$. Yano et al. reported that indigenous spore-forming bacteria increase serotonin synthesis from colon enterochromaffin cells (ECs) [68]. Colons of germ-free mice showed decreased Tph1 expression compared to Tph1 expression in specific pathogen-free mice colon [68]. Serotonin also directly regulates gut microbiota composition [69].

In order to estimate metabolite changes, based on enzyme gene expression, in the gut according to serotonin levels, we performed reporter metabolite analysis, together with metabolic pathway analysis, using R-package piano [70]. The predicted metabolic changes are shown in Supplementary Data 1. Väremo L. et al. developed this gene set analysis method for the interpretation of metabolic and biological functions and pathways from microarray and RNA sequencing data [70]. Figure 6 shows the predicted metabolic changes according to TPH expression in human tissues. TPH1 expression was positively associated with several pathways related to hormone metabolism, xenobiotic metabolism, and nutritional signaling (Figure 6). 

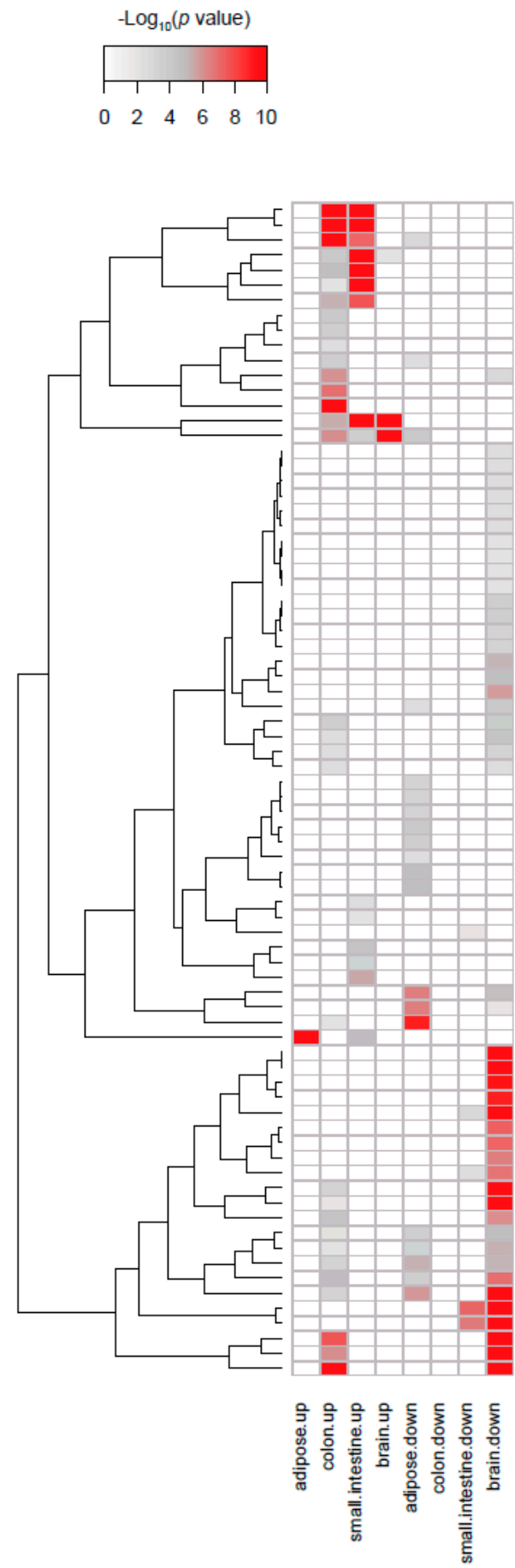

Metabolism of xenobiotics by cytochrome P450 Arachidonic acid metabolism Vitamin E metabolism Steroid metabolism Transport, endoplasmic
Androgen metabolism
Andkotriene metabolism Acylglycerides metabolism Glutathione metabolism Estrogen metabolism Keratan sulfate biosynthesis Retinol metabolism Phenylalanine, tyrosine and tryptophan biosynthesis N-glycan metabolism Glycolysis / Gluconeogenesis
Beta oxidation of phytanic acid (peroxisomal) beta-Alanine metabolism Glycosylphosphatidylinositol (GPI)-anch
Heparan sulfate degradation Nicotinate and nicotinamide metabolism Beta oxidation of branched-chain fatty acids (
Fatty acid elongation (even-chain)
Glycosphingolipid biosynthesis-ganglio series Glycosphingolipid biosynthesis-ganglio series Beta oxidation of oddd-chain fatty acids (peroxisomal) Amino sugar and nucleotide sugar metabolism Fatty acid desaturation (even-chain) Transport, Golgi apparatus Sphingolipid metabolism

Propanoate metabolism
Glycine, serine and threonine metabolism Beta oxidation of unsaturated fatty acids ( $n-9)$ (peroxisomal)
Beta oxidation of di-unsaturated fatty acids ( $n-6$ ) (peroxisomal) Nitrogen metabolism Ascorbate and aldarate metabolism isolated
Fatty acid biosynthesis (even-chain) Porphyrin metabolism Folate metabolism Linoleate metabolism O-glycan metabolism Eicosanoid metabolism
Glucocorticoid biosynthesis Glucocorticoid biosynthesis
Bile acid recycling Oxidative phosphorylation Miscellaneous Glycosphingolipid biosynthesis-lacto and neolacto series Glycerolipid metabolism Beta oxidation of odd-chain fatty acids (mitochondrial)
Beta oxidation of unsaturated fatty acids ( $(n-7)$ (mitochondrial) Transport, nuclear Omega- 6 fatty acid metabolism Transport, mitochondria Aminoacyl-tRNA biosynthesis Tricarboxylic acid cycle and glyoxylate/dicarboxylate metabolism Alanine, aspartate and glutamate metabolism Glycerophospholipid metabolism Pyrimidine metabolism Keratan sulfate degradation Transport, lysosomal
Protein degradation

Figure 6. Predicted metabolic pathways according to TPH1 (adipose tissue, colon, and small intestine) and TPH2 (brain). Figure is the heatmap with the significant changes in metabolic pathway when the high TPH groups were compared with low TPH groups ( $n=10$ per each group). Up: upregulated pathways in high TPH tissue. Down: downregulated pathways in high TPH tissue.

In addition, we also analyzed metabolic profiles in adipose tissue and brain (Figure 6). In the adipose tissues, TPH1 expression shows positive associations with hormonal metabolism and negative associations with mitochondrial FAO pathways. Mitochondrial FAO is the main metabolic pathway against lipid overload in adipose tissue [71]. Enhancing mitochondrial FAO is an emerging therapeutic strategy for obesity treatment [72,73]. ADS increases lipid accumulation in white adipose tissue. Negative correlation between 
TPH1 and mitochondrial FAO in human adipose tissues bears out that inhibiting serotonin synthesis in adipose tissue can be a new therapeutic candidate for obesity therapy [22].

GSA results in the brain displayed that TPH2 has significant associations with mitochondrial FAO pathways, amino acid metabolism, and nucleotide metabolism (Figure 6). These metabolic profiles suggest that serotonin plays an important role in brain development and energy metabolism [74,75]. Clinical studies have already reported the role of serotonin in brain development [76]. Serotonin is involved in neural crest stem cell regulation and is a critical factor in cell survival, growth, differentiation, and synaptogenesis [76]. Alterations in serotonin signaling at an early age resulted in behavior and metal health problems throughout the life span [77].

\section{Discussion}

In this study, we aimed to elucidate the role of serotonin in metabolic changes in human tissues. Here, we used transcriptomic data from the GTEx project [32]. Central serotonin in the human brain regulates fatty acid metabolism and mitochondrial biogenesis and quality control. In addition, central serotonin has a significant association with nucleotide metabolism, which is an important component of neuronal development.

Several studies have reported the protective role of 5-HT in mitochondrial dysfunction. 5-HT increased mitochondrial biogenesis in rodent cortical neurons [61] and mediates mitochondrial stress response in the neurons of C. elegans model [66]. Intriguingly, our data showed that high TPH2 group show lower expression of genes related to mitochondrial functions compared to low TPH2 group (Figure 5). This result implies TPH2 increase in brain could be the result of protective response against mitochondrial dysfunction. Further studies are needed to clarify this association between TPH2 and mitochondrial function.

TPH1 expressions in small intestine and colon have significant associations with hormone and nutrition regulation. This implies that GDS might be the major regulator of endocrine function and metabolic homeostasis in the gut. TPH1 expression in white adipose tissue shows significant associations with mitochondrial FAO and development pathways of other tissues such as the lung and kidney. These results indicate that ADS is a critical factor for endocrine function in white adipose tissue.

Our study has several limitations. First, we did not obtain serotonin levels in human tissues. Thus, we assumed that mRNA expression of TPH might reflect the level of serotonin. If we can directly measure serotonin levels in human tissue, it might be the best way to understand the role of serotonin. Unfortunately, serotonin measurement is very difficult. Serotonin levels in blood and tissue are very low and are rapidly metabolized by monoamine oxidase in living organs [78-80]. Second, we used predicted metabolic profiles by using the GSA method for the evaluation of metabolic pathway changes related to serotonin. Further studies are needed to confirm this result by direct measurement of metabolites in human tissues. Third, we used both omental adipose tissues and subcutaneous adipose tissues when we analyzed white adipose tissue transcriptome. This heterogeneity may act as a confounding factor [81].

In conclusion, our study provides strong evidence that serotonin plays significant roles in critical pathways such as mitochondrial homeostasis, energy metabolism, and organ development.

\section{Material and Methods}

\subsection{Data Collection}

Human brain and peripheral tissue transcriptome data reported in the GTEx Analysis release V8 (dbGap Study Accession: phs000424.v8.p2) were downloaded from the GTEx portal (www.gtexportal.org (accessed on 10 December 2020)) [82]. This dataset includes raw count values that were normalized using the DESeq package in $R$ software.

We also obtained transcripts per million (TPM) values of the GTEx dataset from a public repository, the Human Protein Atlas (http:/ / www.proteinatals.org/about/download 
(accessed on 10 December 2020)). We then estimated the TPH1 and TPH2 expression levels of each human tissue transcriptome.

\subsection{Data Analysis}

We selected the 10 highest and the 10 lowest TPH expression groups from brain, small intestine, colon, and adipose tissue. We then compared gene expression and pathways of interest between the high and low TPH groups. DEGs were identified using the DESeq package in R software. Supplementary data 2 lists the DEGs of our analysis. Volcano plots and heatmaps were obtained using the $\mathrm{R}$ ggplot and gplots package.

The gene set-gene annotation database v7.2 was obtained from the GSEA Molecular Signature Database (https:/ / www.gsea-msigdb.org/gsea/msigdb (accessed on 10 December 2020)). Then, gene set enrichment analysis (GSEA) was performed for gene set association analysis by using the GSEA software [83]. Gene ontology (GO) mining and pathway analysis were performed by the DAIVD gene functional classification tool [84]. Reporter metabolite analysis was performed using the Piano package [70]. The criteria for FDR-adjusted $p$ values $<0.05$ were considered significant gene sets.

Supplementary Materials: The following are available online at https:/ / www.mdpi.com/1422-006 $7 / 22 / 5 / 2452 / s 1$.

Author Contributions: Conceptualization, H.K., S.L., and C.-M.O.; Investigation, S.P., Y.K., J.L. and J.Y.L.; Writing-Original draft, S.P. and C.-M.O.; Writing-Review and editing S.L., and C.-M.O. All authors have read and agreed to the published version of the manuscript.

Funding: This research was supported by the Basic Science Research Program through the National Research Foundation of Korea (NRF) funded by the Ministry of Education (2020R1C1C1004999 to C.M.O.) and supported by Global University Project (GUP to S.L.), "GIST Research Institute (GRI) IIBR" grants (to S.L. and to C.M.O.) funded by the GIST in 2021, and the Bio-Synergy Research Project (2021M3A9C4000991 to S.L.) of the Ministry of Science, ICT through the National Research Foundation.

Institutional Review Board Statement: All data were publicly available or used with approval of the GTEx consortium. Consent was obtained by each corresponding studies.

Informed Consent Statement: Informed consent was waived since we used only publicly available.

Data Availability Statement: The data presented in this study are publicly available on the GTEx portal and HPA portal.

Conflicts of Interest: The authors declare no conflict of interest.

\section{References}

1. Purnell, J.Q. Definitions, classification, and epidemiology of obesity. In Endotext [Internet]; MDText. com, Inc.: South Dartmouth, MA, USA, 2018.

2. Kinlen, D.; Cody, D.; O'Shea, D. Complications of obesity. Qjm Int. J. Med. 2018, 111, 437-443.

3. Kyle, T.K.; Dhurandhar, E.J.; Allison, D.B. Regarding obesity as a disease: Evolving policies and their implications. Endocrinol. Metab. Clin. 2016, 45, 511-520. [CrossRef]

4. Spiegelman, B.M.; Flier, J.S. Obesity and the regulation of energy balance. Cell 2001, 104, 531-543. [CrossRef]

5. Crowley, V.E. Overview of human obesity and central mechanisms regulating energy homeostasis. Ann. Clin. Biochem. 2008, 45, 245-255. [CrossRef]

6. Curran, K.P.; Chalasani, S.H. Serotonin circuits and anxiety: What can invertebrates teach us? Invertebr. Neurosci. 2012, 12, 81-92. [CrossRef] [PubMed]

7. Oh, C.-M.; Park, S.; Kim, H. Serotonin as a new therapeutic target for diabetes mellitus and obesity. Diabetes Metab. J. 2016, 40, 89-98. [CrossRef]

8. Sakowski, S.A.; Geddes, T.J.; Thomas, D.M.; Levi, E.; Hatfield, J.S.; Kuhn, D.M. Differential tissue distribution of tryptophan hydroxylase isoforms 1 and 2 as revealed with monospecific antibodies. Brain Res. 2006, 1085, 11-18. [CrossRef]

9. Del Colle, A.; Israelyan, N.; Gross Margolis, K. Novel aspects of enteric serotonergic signaling in health and brain-gut disease. Am. J. Physiol. -Gastrointest. Liver Physiol. 2020, 318, G130-G143. [CrossRef] [PubMed]

10. Berger, M.; Gray, J.A.; Roth, B.L. The expanded biology of serotonin. Annu. Rev. Med. 2009, 60, 355-366. [CrossRef] [PubMed] 
11. Yabut, J.M.; Crane, J.D.; Green, A.E.; Keating, D.J.; Khan, W.I.; Steinberg, G.R. Emerging roles for serotonin in regulating metabolism: New implications for an ancient molecule. Endocr. Rev. 2019, 40, 1092-1107. [CrossRef]

12. Berglund, E.D.; Liu, C.; Sohn, J.-W.; Liu, T.; Kim, M.H.; Lee, C.E.; Vianna, C.R.; Williams, K.W.; Xu, Y.; Elmquist, J.K. Serotonin $2 \mathrm{C}$ receptors in pro-opiomelanocortin neurons regulate energy and glucose homeostasis. J. Clin. Investig. 2013, 123, 5061-5070. [CrossRef]

13. Mulder, H.; Franke, B.; Arends, J.; Wilmink, F.; Egberts, A.; Scheffer, H. The association between HTR2C polymorphisms and obesity in psychiatric patients using antipsychotics: A cross-sectional study. Pharm. J. 2007, 7, 318-324. [CrossRef] [PubMed]

14. Garfield, A.S.; Davies, J.R.; Burke, L.K.; Furby, H.V.; Wilkinson, L.S.; Heisler, L.K.; Isles, A.R. Increased alternate splicing of Htr2c in a mouse model for Prader-Willi syndrome leads disruption of 5HT 2C receptor mediated appetite. Mol. Brain 2016, 9, 95. [CrossRef]

15. Higgins, G.A.; Fletcher, P.J.; Shanahan, W.R. Lorcaserin: A review of its preclinical and clinical pharmacology and therapeutic potential. Pharmacol. Ther. 2020, 205, 107417. [CrossRef]

16. Mercado, C.P.; Kilic, F. Molecular mechanisms of SERT in platelets: Regulation of plasma serotonin levels. Mol. Interv. 2010, 10, 231. [CrossRef]

17. Eisinger, F.; Patzelt, J.; Langer, H.F. The platelet response to tissue injury. Front. Med. 2018, 5, 317. [CrossRef]

18. Sumara, G.; Sumara, O.; Kim, J.K.; Karsenty, G. Gut-derived serotonin is a multifunctional determinant to fasting adaptation. Cell Metab. 2012, 16, 588-600. [CrossRef] [PubMed]

19. Choi, W.; Namkung, J.; Hwang, I.; Kim, H.; Lim, A.; Park, H.J.; Lee, H.W.; Han, K.-H.; Park, S.; Jeong, J.-S. Serotonin signals through a gut-liver axis to regulate hepatic steatosis. Nat. Commun. 2018, 9, 1-9.

20. Kim, H.; Toyofuku, Y.; Lynn, F.C.; Chak, E.; Uchida, T.; Mizukami, H.; Fujitani, Y.; Kawamori, R.; Miyatsuka, T.; Kosaka, Y. Serotonin regulates pancreatic beta cell mass during pregnancy. Nat. Med. 2010, 16, 804. [CrossRef] [PubMed]

21. Ohara-Imaizumi, M.; Kim, H.; Yoshida, M.; Fujiwara, T.; Aoyagi, K.; Toyofuku, Y.; Nakamichi, Y.; Nishiwaki, C.; Okamura, T.; Uchida, T. Serotonin regulates glucose-stimulated insulin secretion from pancreatic $\beta$ cells during pregnancy. Proc. Natl. Acad. Sci. 2013, 110, 19420-19425. [CrossRef] [PubMed]

22. Oh, C.-M.; Namkung, J.; Go, Y.; Shong, K.E.; Kim, K.; Kim, H.; Park, B.-Y.; Lee, H.W.; Jeon, Y.H.; Song, J. Regulation of systemic energy homeostasis by serotonin in adipose tissues. Nat. Commun. 2015, 6, 1-12. [CrossRef] [PubMed]

23. Shong, K.E.; Oh, C.-M.; Namkung, J.; Park, S.; Kim, H. Serotonin regulates de novo lipogenesis in adipose tissues through serotonin receptor 2A. Endocrinol. Metab. 2020, 35, 470-479. [CrossRef] [PubMed]

24. Martin, A.M.; Yabut, J.M.; Choo, J.M.; Page, A.J.; Sun, E.W.; Jessup, C.F.; Wesselingh, S.L.; Khan, W.I.; Rogers, G.B.; Steinberg, G.R. The gut microbiome regulates host glucose homeostasis via peripheral serotonin. Proc. Natl. Acad. Sci. USA 2019, 116, 19802-19804. [CrossRef]

25. Kaur, H.; Bose, C.; Mande, S.S. Tryptophan metabolism by gut microbiome and gut-brain-axis: An in silico Analysis. Front. Neurosci. 2019, 13, 1365. [CrossRef]

26. Zhao, J.; Goldberg, J.; Vaccarino, V. Promoter methylation of serotonin transporter gene is associated with obesity measures: A monozygotic twin study. Int. J. Obes. 2013, 37, 140-145. [CrossRef]

27. Perez-Cornago, A.; Mansego, M.L.; Zulet, M.A.; Martinez, J.A. DNA hypermethylation of the serotonin receptor type-2A gene is associated with a worse response to a weight loss intervention in subjects with metabolic syndrome. Nutrients 2014, 6, 2387-2403 [CrossRef] [PubMed]

28. Kring, S.I.; Werge, T.; Holst, C.; Toubro, S.; Astrup, A.; Hansen, T.; Pedersen, O.; Sørensen, T.I. Polymorphisms of serotonin receptor 2A and 2C genes and COMT in relation to obesity and type 2 diabetes. PLoS ONE 2009, 4, e6696. [CrossRef] [PubMed]

29. Kwak, S.H.; Park, B.L.; Kim, H.; German, M.S.; Go, M.J.; Jung, H.S.; Koo, B.K.; Cho, Y.M.; Choi, S.H.; Cho, Y.S. Association of variations in TPH1 and HTR2B with gestational weight gain and measures of obesity. Obesity 2012, 20, 233-238. [CrossRef] [PubMed]

30. Young, R.L.; Lumsden, A.L.; Martin, A.M.; Schober, G.; Pezos, N.; Thazhath, S.S.; Isaacs, N.J.; Cvijanovic, N.; Sun, E.W.; Wu, T. Augmented capacity for peripheral serotonin release in human obesity. Int. J. Obes. 2018, 42, 1880-1889. [CrossRef]

31. Lumsden, A.L.; Martin, A.M.; Sun, E.W.; Schober, G.; Isaacs, N.J.; Pezos, N.; Wattchow, D.A.; de Fontgalland, D.; Rabbitt, P.; Hollington, P. Sugar responses of human enterochromaffin cells depend on gut region, sex, and body mass. Nutrients 2019, 11, 234. [CrossRef]

32. Consortium, G. Genetic effects on gene expression across human tissues. Nature 2017, 550, 204-213. [CrossRef]

33. Joh, T. Tryptophan hydroxylase: Molecular biology and regulation. In Serotoninergic Neurons and 5-HT Receptors in the CNS; Springer: Berlin/Heidelberg, Germany, 2000; pp. 117-129.

34. Matthes, S.; Bader, M. Peripheral serotonin synthesis as a new drug target. Trends Pharmacol. Sci. 2018, 39, 560-572. [CrossRef] [PubMed]

35. Bach-Mizrachi, H.; Underwood, M.D.; Kassir, S.A.; Bakalian, M.J.; Sibille, E.; Tamir, H.; Mann, J.J.; Arango, V. Neuronal tryptophan hydroxylase mRNA expression in the human dorsal and median raphe nuclei: Major depression and suicide. Neuropsychopharmacology 2006, 31, 814-824. [CrossRef]

36. Chen, G.L.; Miller, G.M. Advances in tryptophan hydroxylase-2 gene expression regulation: New insights into serotonin-stress interaction and clinical implications. Am. J. Med Genet. Part B Neuropsychiatr. Genet. 2012, 159, 152-171. [CrossRef] [PubMed] 
37. Zill, P.; Büttner, A.; Eisenmenger, W.; Müller, J.; Möller, H.-J.; Bondy, B. Predominant expression of tryptophan hydroxylase 1 mRNA in the pituitary: A postmortem study in human brain. Neuroscience 2009, 159, 1274-1282. [CrossRef]

38. Zill, P.; Büttner, A.; Eisenmenger, W.; Möller, H.-J.; Ackenheil, M.; Bondy, B. Analysis of tryptophan hydroxylase I and II mRNA expression in the human brain: A post-mortem study. J. Psychiatr. Res. 2007, 41, 168-173. [CrossRef]

39. Kawabata-Sakata, Y.; Nishiike, Y.; Fleming, T.; Kikuchi, Y.; Okubo, K. Androgen-dependent sexual dimorphism in pituitary tryptophan hydroxylase expression: Relevance to sex differences in pituitary hormones. Proc. R. Soc. B 2020, 287, 20200713. [CrossRef] [PubMed]

40. Ali, A.T.; Hochfeld, W.E.; Myburgh, R.; Pepper, M.S. Adipocyte and adipogenesis. Eur. J. Cell Biol. 2013, 92, 229-236. [CrossRef] [PubMed]

41. Yang, J.; Li, X.; Xu, D. Research Progress on the Involvement of ANGPTL4 and Loss-of-Function Variants in Lipid Metabolism and Coronary Heart Disease: Is the "Prime Time" of ANGPTL4-Targeted Therapy for Coronary Heart Disease Approaching? Cardiovasc. Drugs Ther. 2020, 1-11. [CrossRef]

42. Bruce, K.D.; Zsombok, A.; Eckel, R.H. Lipid processing in the brain: A key regulator of systemic metabolism. Front. Endocrinol. 2017, 8, 60. [CrossRef]

43. Terry, N.; Margolis, K.G. Serotonergic mechanisms regulating the GI tract: Experimental evidence and therapeutic relevance. In Gastrointestinal Pharmacology; Springer: Berlin/Heidelberg, Germany, 2016; pp. 319-342.

44. Yadav, V.K.; Balaji, S.; Suresh, P.S.; Liu, X.S.; Lu, X.; Li, Z.; Guo, X.E.; Mann, J.J.; Balapure, A.K.; Gershon, M.D. Pharmacological inhibition of gut-derived serotonin synthesis is a potential bone anabolic treatment for osteoporosis. Nat. Med. 2010, 16, 308. [CrossRef]

45. Kim, K.; Oh, C.-M.; Ohara-Imaizumi, M.; Park, S.; Namkung, J.; Yadav, V.K.; Tamarina, N.A.; Roe, M.W.; Philipson, L.H.; Karsenty, G. Functional role of serotonin in insulin secretion in a diet-induced insulin-resistant state. Endocrinology 2015, 156, 444-452. [CrossRef] [PubMed]

46. Ahlman, H.; Nilsson, O. The gut as the largest endocrine organ in the body. Ann. Oncol. 2001, 12, S63-S68. [CrossRef]

47. Chen, C.; Fang, R.; Davis, C.; Maravelias, C.; Sibley, E. Pdx1 inactivation restricted to the intestinal epithelium in mice alters duodenal gene expression in enterocytes and enteroendocrine cells. Am. J. Physiol. -Gastrointest. Liver Physiol. 2009, 297, G1126-G1137. [CrossRef] [PubMed]

48. Jenny, M.; Uhl, C.; Roche, C.; Duluc, I.; Guillermin, V.; Guillemot, F.; Jensen, J.; Kedinger, M.; Gradwohl, G. Neurogenin3 is differentially required for endocrine cell fate specification in the intestinal and gastric epithelium. EMBO J. 2002, 21, 6338-6347. [CrossRef] [PubMed]

49. Jančík, S.; Drábek, J.; Radzioch, D.; Hajdúch, M. Clinical relevance of KRAS in human cancers. J. Biomed. Biotechnol. 2010, 2010, 150960. [CrossRef]

50. Carvalho, P.D.; Guimarães, C.F.; Cardoso, A.P.; Mendonça, S.; Costa, Â.M.; Oliveira, M.J.; Velho, S. KRAS oncogenic signaling extends beyond cancer cells to orchestrate the microenvironment. Cancer Res. 2018, 78, 7-14. [CrossRef] [PubMed]

51. Wan, X.-B.; Wang, A.-Q.; Cao, J.; Dong, Z.-C.; Li, N.; Yang, S.; Sun, M.-M.; Li, Z.; Luo, S.-X. Relationships among KRAS mutation status, expression of RAS pathway signaling molecules, and clinicopathological features and prognosis of patients with colorectal cancer. World J. Gastroenterol. 2019, 25, 808. [CrossRef] [PubMed]

52. Kannen, V.; Bader, M.; Sakita, J.Y.; Uyemura, S.A.; Squire, J.A. The dual role of serotonin in colorectal cancer. Trends Endocrinol. Metab. 2020. [CrossRef] [PubMed]

53. Tutton, P.; Barkla, D. The influence of serotonin on the mitotic rate in the colonic crypt epithelium and in colonic adenocarcinoma in rats. Clin. Exp. Pharmacol. Physiol. 1978, 5, 91-94. [CrossRef]

54. Ballou, Y.; Rivas, A.; Belmont, A.; Patel, L.; Amaya, C.N.; Lipson, S.; Khayou, T.; Dickerson, E.B.; Nahleh, Z.; Bryan, B.A. 5-HT serotonin receptors modulate mitogenic signaling and impact tumor cell viability. Mol. Clin. Oncol. 2018, 9, 243-254. [CrossRef]

55. Ono, K.; Horie, T.; Abe, Y.; Kawamura, T.; Shimatsu, A.; Hasegawa, K.; Kita, T. Adipocyte-derived Serotonin Regulates Adipocyte Differentiation Via an Autocrine/Paracrine Mechanism. J. Card. Fail. 2006, 12, S171. [CrossRef]

56. Oguri, M.; Kato, K.; Horibe, H.; Fujimaki, T.; Sakuma, J.; Takeuchi, I.; Murohara, T.; Yasukochi, Y.; Yamada, Y. Identification of two genes as novel susceptibility loci for type 2 diabetes mellitus in Japanese. Eur. Heart J. 2020, 41, ehaa946. 2813. [CrossRef]

57. Zegers, D.; Beckers, S.; Hendrickx, R.; Van Camp, J.; De Craemer, V.; Verrijken, A.; Van Hoorenbeeck, K.; Verhulst, S.; Rooman, R.; Desager, K. Mutation screen of the SIM1 gene in pediatric patients with early-onset obesity. Int. J. Obes. 2014, 38, 1000-1004. [CrossRef] [PubMed]

58. Moon, J.H.; Kim, H.; Kim, H.; Park, J.; Choi, W.; Choi, W.; Hong, H.J.; Ro, H.-J.; Jun, S.; Choi, S.H. Lactation improves pancreatic $\beta$ cell mass and function through serotonin production. Sci. Transl. Med. 2020, 12, eaay0455. [CrossRef]

59. Sun, C.; Kilburn, D.; Lukashin, A.; Crowell, T.; Gardner, H.; Brundiers, R.; Diefenbach, B.; Carulli, J.P. Kirrel2, a novel immunoglobulin superfamily gene expressed primarily in $\beta$ cells of the pancreatic islets 5 . Genomics 2003, 82, 130-142. [CrossRef]

60. Yesildag, B.; Bock, T.; Herrmanns, K.; Wollscheid, B.; Stoffel, M. Kin of IRRE-like protein 2 is a phosphorylated glycoprotein that regulates basal insulin secretion. J. Biol. Chem. 2015, 290, 25891-25906. [CrossRef] [PubMed]

61. Fanibunda, S.E.; Deb, S.; Maniyadath, B.; Tiwari, P.; Ghai, U.; Gupta, S.; Figueiredo, D.; Weisstaub, N.; Gingrich, J.A.; Vaidya, A.D. Serotonin regulates mitochondrial biogenesis and function in rodent cortical neurons via the 5-HT2A receptor and SIRT1-PGC-1 $\alpha$ axis. Proc. Natl. Acad. Sci. USA 2019, 116, 11028-11037. [CrossRef] 
62. Sola-Penna, M.; Paixão, L.P.; Branco, J.R.; Ochioni, A.C.; Albanese, J.M.; Mundim, D.M.; Baptista-de-Souza, D.; Figueiredo, C.P.; Coelho, W.S.; Marcondes, M.C. Serotonin activates glycolysis and mitochondria biogenesis in human breast cancer cells through activation of the Jak1/STAT3/ERK1/2 and adenylate cyclase/PKA, respectively. Br. J. Cancer 2020, 122, 194-208. [CrossRef]

63. Wang, Q.; Zhang, H.; Xu, H.; Guo, D.; Shi, H.; Li, Y.; Zhang, W.; Gu, Y. 5-HTR3 and 5-HTR4 located on the mitochondrial membrane and functionally regulated mitochondrial functions. Sci. Rep. 2016, 6, 37336. [CrossRef] [PubMed]

64. Yang, Y.; Huang, H.; Xu, Z.; Duan, J.-k. Serotonin and its receptor as a new antioxidant therapeutic target for diabetic kidney disease. J. Diabetes Res. 2017, 2017, 7680576. [CrossRef]

65. Muñoz-Castañeda, J.R.; Montilla, P.; Padillo, F.J.; Bujalance, I.; Muñoz, M.C.; Muntané, J.; Túnez, I. Role of serotonin in cerebral oxidative stress in rats. Acta Neurobiol. Exp. 2006, 66, 1-6.

66. Berendzen, K.M.; Durieux, J.; Shao, L.-W.; Tian, Y.; Kim, H.-e.; Wolff, S.; Liu, Y.; Dillin, A. Neuroendocrine coordination of mitochondrial stress signaling and proteostasis. Cell 2016, 166, 1553-1563. e1510. [CrossRef]

67. Zhang, Q.; Wu, X.; Chen, P.; Liu, L.; Xin, N.; Tian, Y.; Dillin, A. The mitochondrial unfolded protein response is mediated cell-non-autonomously by retromer-dependent Wnt signaling. Cell 2018, 174, 870-883. e817. [CrossRef]

68. Yano, J.M.; Yu, K.; Donaldson, G.P.; Shastri, G.G.; Ann, P.; Ma, L.; Nagler, C.R.; Ismagilov, R.F.; Mazmanian, S.K.; Hsiao, E.Y. Indigenous bacteria from the gut microbiota regulate host serotonin biosynthesis. Cell 2015, 161, 264-276. [CrossRef] [PubMed]

69. Kwon, Y.H.; Wang, H.; Denou, E.; Ghia, J.-E.; Rossi, L.; Fontes, M.E.; Bernier, S.P.; Shajib, M.S.; Banskota, S.; Collins, S.M. Modulation of gut microbiota composition by serotonin signaling influences intestinal immune response and susceptibility to colitis. Cell. Mol. Gastroenterol. Hepatol. 2019, 7, 709-728. [CrossRef] [PubMed]

70. Väremo, L.; Nielsen, J.; Nookaew, I. Enriching the gene set analysis of genome-wide data by incorporating directionality of gene expression and combining statistical hypotheses and methods. Nucleic Acids Res. 2013, 41, 4378-4391. [CrossRef] [PubMed]

71. Malandrino, M.I.; Fucho, R.; Weber, M.; Calderon-Dominguez, M.; Mir, J.F.; Valcarcel, L.; Escoté, X.; Gómez-Serrano, M.; Peral, B.; Salvadó, L. Enhanced fatty acid oxidation in adipocytes and macrophages reduces lipid-induced triglyceride accumulation and inflammation. Am. J. Physiol. Endocrinol. Metab. 2015, 308, E756-E769. [CrossRef] [PubMed]

72. Serra, D.; Mera, P.; Malandrino, M.I.; Mir, J.F.; Herrero, L. Mitochondrial fatty acid oxidation in obesity. Antioxid. Redox Signal. 2013, 19, 269-284. [CrossRef] [PubMed]

73. Bruce, C.R.; Thrush, A.B.; Mertz, V.A.; Bezaire, V.; Chabowski, A.; Heigenhauser, G.J.; Dyck, D.J. Endurance training in obese humans improves glucose tolerance and mitochondrial fatty acid oxidation and alters muscle lipid content. Am. J. Physiol. Endocrinol. Metab. 2006, 291, E99-E107. [CrossRef]

74. Fumagalli, M.; Lecca, D.; Abbracchio, M.P.; Ceruti, S. Pathophysiological role of purines and pyrimidines in neurodevelopment: Unveiling new pharmacological approaches to congenital brain diseases. Front. Pharmacol. 2017, 8, 941. [CrossRef]

75. Ipata, P.L. Origin, utilization, and recycling of nucleosides in the central nervous system. Adv. Physiol. Educ. 2011, 35, 342-346. [CrossRef] [PubMed]

76. Shah, R.; Courtiol, E.; Castellanos, F.X.; Teixeira, C.M. Abnormal serotonin levels during perinatal development lead to behavioral deficits in adulthood. Front. Behav. Neurosci. 2018, 12, 114. [CrossRef] [PubMed]

77. Brummelte, S.; Mc Glanaghy, E.; Bonnin, A.; Oberlander, T. Developmental changes in serotonin signaling: Implications for early brain function, behavior and adaptation. Neuroscience 2017, 342, 212-231. [CrossRef]

78. Fitzgerald, L.W.; Kaplinsky, L.; Kimelberg, H.K. Serotonin metabolism by monoamine oxidase in rat primary astrocyte cultures. J. Neurochem. 1990, 55, 2008-2014. [CrossRef] [PubMed]

79. Visser, A.K.; van Waarde, A.; Willemsen, A.T.; Bosker, F.J.; Luiten, P.G.; den Boer, J.A.; Kema, I.P.; Dierckx, R.A. Measuring serotonin synthesis: From conventional methods to PET tracers and their (pre) clinical implications. Eur. J. Nucl. Med. Mol. Imaging 2011, 38, 576-591. [CrossRef]

80. Lee, G.S.; Simpson, C.; Sun, B.H.; Yao, C.; Foer, D.; Sullivan, B.; Matthes, S.; Alenina, N.; Belsky, J.; Bader, M. Measurement of plasma, serum, and platelet serotonin in individuals with high bone mass and mutations in LRP5. J. Bone Miner. Res. 2014, 29, 976-981. [CrossRef] [PubMed]

81. Kwok, K.H.; Lam, K.S.; Xu, A. Heterogeneity of white adipose tissue: Molecular basis and clinical implications. Exp. Mol. Med. 2016, 48, e215. [CrossRef]

82. Goldman, M.J.; Craft, B.; Hastie, M.; Repečka, K.; McDade, F.; Kamath, A.; Banerjee, A.; Luo, Y.; Rogers, D.; Brooks, A.N. Visualizing and interpreting cancer genomics data via the Xena platform. Nat. Biotechnol. 2020, 38, 675-678. [CrossRef]

83. Subramanian, A.; Tamayo, P.; Mootha, V.K.; Mukherjee, S.; Ebert, B.L.; Gillette, M.A.; Paulovich, A.; Pomeroy, S.L.; Golub, T.R.; Lander, E.S. Gene set enrichment analysis: A knowledge-based approach for interpreting genome-wide expression profiles. Proc. Natl. Acad. Sci. USA 2005, 102, 15545-15550. [CrossRef] [PubMed]

84. Sherman, B.T.; Tan, Q.; Collins, J.R.; Alvord, W.G.; Roayaei, J.; Stephens, R.; Baseler, M.W.; Lane, H.C.; Lempicki, R.A. The DAVID Gene Functional Classification Tool: A novel biological module-centric algorithm to functionally analyze large gene lists. Genome Biol. 2007, 8, R183. 